\title{
PROFESSIONAL REGULATION - INCOHERENT, EXPENSIVE AND INEFFECTIVE
}

The BDJ Upfront section includes editorials, letters, news, book reviews and interviews.

Please direct your correspondence to the News Editor, David Westgarth at the BDJ The Macmillan Building, 4 Crinan Street, London, N1 9XW or by email to BDJNews@nature.com

Press releases or articles may be edited, and should include a colour photograph if possible.

\author{
Peter Ward
}

Chief Executive, BDA

$\mathrm{T}$ Professional Standards Authority's (PSA) paper Rethinking regulation (https:// www.professionalstandards.org.uk) raises fundamental questions about the ways in which the whole of health and social care in the UK is regulated. Clearly intended to be a provocative piece, it is well-researched and robustly reasoned, challenging the existing landscape. We have nine different regulators, with nine different approaches to regulation and interpretations of remits.

The report recognises that modern healthcare is complex and asks whether the silos that have been built around 'nurses', 'dentists' and 'doctors' even reflects the reality of care in twenty-first century Britain. There are now two streams of regulation; one covering individuals and another the organisations that corporately deliver health and social care. The question is posed as to why there is not a much greater integration of regulation operating in parallel so gaps and overlaps can be avoided.

The paper also goes to the fundamental principles of why regulation exists in the first place. It questions proportionality and risk. Innovation always means stepping outside conventional ways of doing things and creating new approaches. Any system which impedes that innovation may offer greater predictability but also stifles clinical advancement. Systems that make practitioners fearful of occasionally stepping beyond the established paradigm for concern of sanctions cannot be deemed to be acting in the interests of patients. Indeed were such constraints to have been placed upon the early exponents of medicine and surgery near-miraculous clinical interventions, from which we all now benefit, may never have evolved.

\section{'Regulators \\ must remember that their concern is not quality improve- ment but quality control...'}

The authors say: 'We must seek to understand what motivates individuals, teams and organisations to succeed, not attempt to frighten them to resentful compliance.' The fact that this statement resonates so loudly signifies two important things. Firstly, that we have got to a place where this even needs to be articulated tells us how bad things have become. It affirms that this is indeed the culture which so many clinicians are enduring. But even more importantly is that this is also demonstrably disadvantaging the intended beneficiaries - the patients.

The staggering growth in organisational regulation over the period now reveals an annual bill of $£ 600$ million per year, quite aside from the costs incurred by the establishments themselves in delivering the compliance. If we conservatively estimate that the organisations are spending at least the same again, we are into expenditure of billions of pounds that could be used to deliver healthcare rather than to measure it in such a destructive way.

But perhaps the most telling component of the paper is its recognition that the professional regulators themselves have their own organisational personalities. The lack of a coherent approach means that the self-same recipients of clinical interventions in different disciplines are likely to be treated by clinicians who are the subject of highly differentiated interpretations of what is professionally acceptable. Beyond this, the ambitions of the regulators themselves is also considered. The PSA reports: 'Too often we have seen examples of regulatory mission creep, where regulators have sought to expand the boundaries of their activity in ways that have resulted in confusion for the public and internal conflict of interest'.
This idea of the regulators having their own foibles and misdirection then begs the question of motivation. When statutory descriptions of roles are fairly unambiguous why do some stray outside these boundaries? Is it genuine misunderstanding or are there personal ambitions and egos at play? Whilst it may be true that the legislation is outdated, it most certainly isn't unclear. Indeed this report reaffirms the point that 'regulators must remember that their concern is not quality improvement but quality control'. Once again, that the paper has to issue this reminder is telling as it demonstrates that over-reaching and mission creep appears to be the order of the day.

The report remains silent on funding, but it can be no accident that this differentiation of interpretation and wilful empire building exists in a sector that does not rely upon taxpayers for income. That registrants themselves pay for the privilege of being regulated and that regulators appear to be able to charge whatever they like means that ambitions can be limitless. The absence of exposure to the Public Accounts Committee means that wrongheadedness, personal distrust or ambitious land-grabbing can all be funded without any constraint.

While this PSA paper goes well beyond dentistry, the assertions it makes are entirely apposite to us. We have seen the excesses of an underperforming regulator out of control. We have seen what appear to be pet projects overwhelming real purpose across the board. The whole system looks like it needs to change, and we now have a document that sets some firm foundations for a needed debate to kick start that change.

As dentists, as the BDA, we will be at the heart of that debate.

DOI: 10.1038/sj.bdj.2015.637 